\title{
Traffic Accident Cost Analysis Using Willingness-to-pay Method in Surabaya
}

\author{
Ahmad Utanaka, Hera Widyastuti
}

\begin{abstract}
There are some methods to determine accident cost, one of which is the willingness-to-pay method. Willingness-to-pay method use in this research because this method more recommended by developed countries than gross output method which is still used in developing countries, especially Indonesia. Road traffic accident is one of the top $\mathbf{1 0}$ causes of death because motorcycle drivers are vulnerable and have a high-risk probability for traffic accidents. Location of this study is at Surabaya City which is the second biggest city in Indonesia because the frequency of accidents is increasing every year. This research began by collecting accident data, demography of Surabaya, price and lifetime of motorcycle tires, and perform stated preference survey to receive the willingness-to-pay value. Selection of decisions in replacing and maintaining tires can determine different willingness-to-pay value. This research analyzes willingness-to-pay value using the discrete choice method and reduces the risk probability of traffic accidents for themselves.
\end{abstract}

Index Terms - Accident cost, discrete choice, road traffic accident, Surabaya, willingness-to-pay

\section{INTRODUCTION}

$\mathrm{S}$ urabaya is the second biggest city in Indonesia after DKI Jakarta. The development of Surabaya City especially in the economic sector is influenced by road development. Currently, the road network in Surabaya has been too complex, the mobility of the population was very high as well [1]. According to traffic accident data by Directorate of Traffic and City Resort Police of Surabaya (the year 2014 2016) shows an increase of the frequency of road traffic accidents each year. In 2014 there are 716 accidents, in 2015 there are 879 accidents, and in 2016 there are 1126 accidents. Accidents can occur due to several factors i.e. human, vehicles, and roads factors [2]. Road traffic accident is one of the leading cause of death, even it is one of the top 10 causes of death in the world beside medical factor (such as heart disease, stroke, diabetes, etc.) [3-5]. This is because motorcycle drivers are vulnerable and have a high-risk probability of traffic accidents [6-9]. Of all the victims of traffic accidents, the most victims are motorcycle driver. Based on traffic accident data in one year (for example in 2017), the number of accident victims who are motorcycle

Ahmad Utanaka is with The Department of Civil Engineering, Institut Teknologi Sepuluh Nopember, 60111, Surabaya, East Java, Indonesia

Hera Widyastuti is with The Department of Civil Engineering, Institut Teknologi Sepuluh Nopember, 60111, Surabaya, East Java, Indonesia (e-mail: hera.widyastuti@yahoo.co.uk) drivers are 1813 people, where almost 4 times accident victims who are car drivers, i.e. only 509 people. Because of the high accidents that occur, it is necessary to do a study to find out the level of driver's awareness to reduce the risk of accidents. In this study, it is using the willingness-to-pay (WTP) method. WTP method is selected because this method already used in developed countries and it is recommended to be used in developing countries to calculate accident costs $[6$, 10].

\section{LITERATURE REVIEW}

The willingness-to-pay approach looks at the ways in which individuals are willing to pay to avoid accidents [11]. This approach is preferable because at this time many countries have moved to the willingness-to-pay approach than gross output approach and the willingness-to-pay approach has been done in Indonesia [6].

In this study, analysis using the discrete choice method to model the willingness-to-pay approach. The result from the discrete choice that used describes preferences and choices in terms of the probability of choosing each alternative [10]. These probabilities reflect the population probability that people with certain characteristics and facing the same set of alternatives by choosing each alternative [12].

The utility functions can be formulated as follow [10]:

$$
U=V+\varepsilon=\beta^{\prime} x+\varepsilon
$$

$U=$ the utility of willing to pay the amount for severity reduction

$V$ = the systematic (deterministic) component of the utility of willing to pay the amount for severity reduction

$\varepsilon=$ the random (disturbance or error) component of the utility of willing to pay the amount for severity reduction

$x=$ the vector of attributes that are related to the willingness to pay the amount for severity reduction

$\beta^{\prime}=$ the vector of unknown parameters

Ben-Akiva and Lerman approach (1985) see the utility of each alternative as a random variable where if any alternative $i$ choose by person $n$ from the choice set $C_{n}$, the probability $P_{i n}$ given by [13] :

$$
P_{\text {in }}=P\left(U_{\text {in }} \geq U_{j n} \quad \forall j \in C_{n}, j \neq i\right)
$$

$P_{i n}=$ probability that the individual $n$ chooses alternative $i$ $U_{i n}=$ utility function of the individual $n$ chooses alternative $i$ 
$\forall j=$ all the cases, $J$, in the choice set $C_{n}$ : chooses alternative $n$

Applying the formula into binary choices which symbolize the choice sets $C_{n}$ as $i$ and $j$, then the probability of people choosing alternative $i$ is

$P_{n}\left(i / C_{n}\right)=P_{r}\left(U_{\text {in }} \geq U_{j n}\right)$

And the probability of people choosing alternative $j$ is $P_{n}(j)=1-P_{n}(i)$

Logistically distributed, the choice probability of alternative $i$ binary logit is

$P_{n}(j)=P_{r}\left(U_{i n} \geq U_{j n}\right)$

$=\frac{1}{1+e^{-\pi\left(V_{i n}-V_{j n}\right)}}$

$=\frac{e^{\pi V_{i n}}}{e^{\pi V_{i n}}+e^{\pi V_{j n}}}$

The choice probability of the binary model is estimated based on

$p=\frac{\exp ^{\log i t}(p)}{1+\exp ^{\log i t}(p)}$

In other words

$p=\frac{\text { probability }}{1+\text { probability }}$

The choice probability for the willingness to pay the amount for severity reduction can be written as follows:

$P_{n}(i)=P_{y e s}=\frac{e^{\beta \prime x y e s}}{e^{\beta \prime x y e s}+e^{\beta \prime x} y e s}$

Which:

$P_{n}(i)=$ the probability that individual $n$ has chosen the option to pay the specified amount

for severity reduction

\section{MATERIALS AND METHOD}

Location of this study is at Surabaya City. Data used in this study are the number of the traffic accident, demography of Surabaya City, price and lifetime of motorcycle tires, and willingness-to-pay value from stated preference survey.

In outline, the stages in this study are divided into 4 stages, preparation and literature review, data collection, analysis and discussion, and conclusion. Method of collecting data using stated preference method. Which involves surveys to determine the individual's willingness to pay for products or attributes in a hypothetical situation [11]. Respondents are the citizen of Surabaya City who were interviewed randomly. Interview the interview is done in the center of the crowd of Surabaya City i.e city park, food court, etc. Variables taken are age, income, number of children, and willingness-to-pay choices. After the data collected, then performed data analysis. Data analyzed using the discrete choice method using binary logit model.

\section{RESULTS AND DISCUSSIONS}

\section{A. Characteristic of Respondents}

Data collected by performing stated preference survey to citizens of Surabaya randomly. the characteristics obtained based on survey results are as follows.

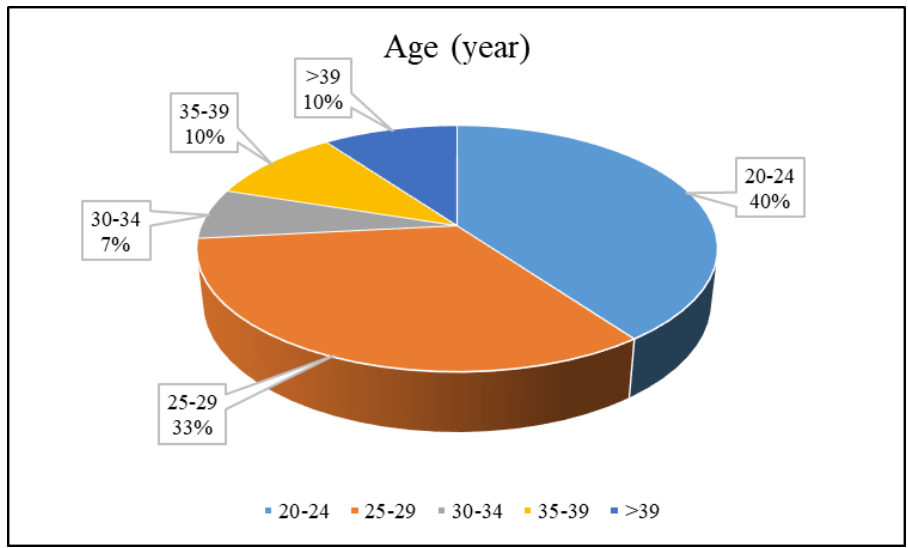

Fig. 1. Characteristic of respondents based on age

The figure above shows the percentage of respondents dominated by age $25-29$ years as big as $35 \%$ and the smallest percentage is age more than 39 years old as big as $10 \%$.

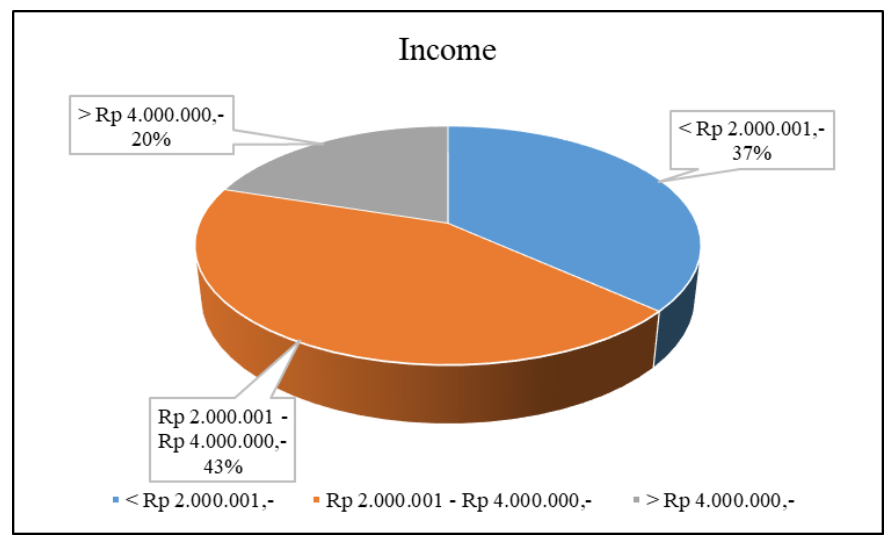

Fig. 2. Characteristic of respondents based income

The figure above shows the percentage of respondents dominated by income between $\mathrm{Rp} 2.000 .000,-$ and $\mathrm{Rp}$ 4.000 .000 ,- as big as $43 \%$. It means the minimum wage for workers in Surabaya City has been fulfilled. 


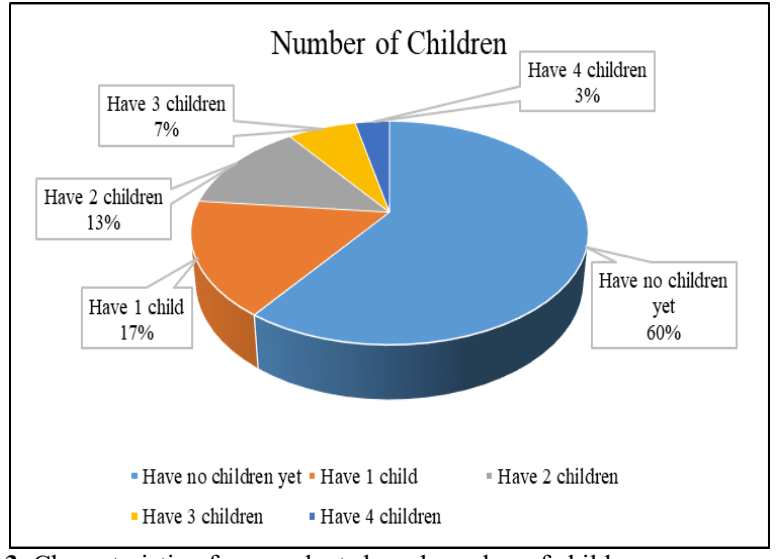

Fig. 3. Characteristic of respondents based number of children

The figure above shows the percentage of respondents dominated with have no children yet as big as $60 \%$. This is caused by age of respondents is still relatively young.

\section{B. Willingness to Pay Choices}

Two hypotheses option to reduces traffic accident given to the respondents to be selected. Two options that are given are the reduction of accident risk by $25 \%$ and $50 \%$ which can be seen in Table I.

TABLE I

WILLINGNESS-TO-PAY CHOICES OR ACCIDENT REDUCTION

\begin{tabular}{ccc}
\hline Willingness-to-pay choices & \multicolumn{2}{c}{ Additional cost } \\
\hline $25 \%$ reduction & Rp 2.300,- & Rp 0,-
\end{tabular}

$50 \%$ reduction $\quad \operatorname{Rp} 4.600,-\quad R p 0,-$

An example of one willingness-to-pay choice that given to respondents can be seen in the following table.

TABLE II

QUESTIONNAIRE WILLINGNESS-TO PAY CHOICE

\begin{tabular}{lll}
\hline Criteria & Option A & Option B \\
\hline Maximum possible speed (km/jam) & 70 & 60 \\
Change tire in every (month) & 54 & 60 \\
The probability for the slight injury & $56 / 100.000$ & $74 / 100.000$ \\
Additional cost (Rp) & 2.300 & 0 \\
Selected alternative & & \\
\hline
\end{tabular}

\section{Analysis of The Discrete Choice Model}

Many previous studies mention that income, age and number of children are the variables that influence the individual's willingness to pay and the model [10], [14-17]. But, in this study age variable is not significant, so it only uses income and number of children variable. According to survey results, all respondents choose the same option for $25 \%$ reduction and $50 \%$ reduction so it gives the same result. Data survey results are analyzed using the SPSS program and give the values as the table below.
TABLE III

THE RESUlt OF THE MODEL FOR 25\% AND 50\% SLIGHT INJURY PREVENTION

\begin{tabular}{cccc}
\hline Variable & Parameter & p-value & Exp $(\beta)$ \\
\hline Income & 2.720 & 0.025 & 15.176 \\
Number of children & -1.797 & 0.014 & 0.166 \\
Constant & -2.414 & 0.111 & 0.089 \\
\hline
\end{tabular}

Based on the above table, all independent variables p-value $<0.05$ it means that each variable has a significant partial effect on $y$ in the model. Income has p-value $0.025<0.050$ and number of children has p-value $0.014<0.050$, thus rejecting $\mathrm{H}_{0}$ or which means a significant partial effect.

According to $\operatorname{Exp}(\beta)$ value, the probability of willing to pay from respondents with higher income is 15.176 times higher than respondents with lower income. While for the probability of willing to pay from respondents with the lower number of children in 0.166 higher than respondents with the higher number of children.

Based on the parameter values obtained, then the equation model formed as follows :

Logit $(p)=\ln \left(\frac{p}{1-p}\right)=-2.414+2.720$ Income -1.797

Number of children

From model above, it can be interpreted that every single unit change of income variable will increase willingness-topay $\log$ probability as big as 2.720 , while for each one unit change of the number of children variable will decrease willingness-to-pay log probability as big as 1.797 .

It can calculate the probability from the model above of a person willing to pay to reduce the risk by $25 \%$ and $50 \%$ slight motorcycle injuries. For example, if a person has income $\mathrm{Rp} \mathrm{3.580.000,-}$ which is the minimum wage of Surabaya City [18] and has 3 children, substitute the values of income and number of children in the equation. Then the probability of a person willing to pay to reduce the risk can be obtained.

Logit $(p)=\ln \left(\frac{p}{1-p}\right)=-2.414+2.720$ Income -1.797

Number of children

Logit $(p)=\ln \left(\frac{p}{1-p}\right)=-2.414+2.720 \times 3580000 / 1000000-$

$1.797 \times 3=1.933$

Then the probability is

$p=\frac{\exp ^{\operatorname{logit}(p)}}{1+\exp ^{\log \text { it }(p)}}=\frac{\exp ^{1.933}}{1+\exp ^{1.933}}=0.874$

The interpretation is if a person would be willing to pay for their own safety to reduce the risk of the motorcycle accident, then the probability is $87.4 \%$. But, if with different income and number of children value, it will obtain different probability.

Logit $(p)=\ln \left(\frac{p}{1-p}\right)=-2.414+2.720$ Income -1.797

Number of children

Logit $(p)=\ln \left(\frac{p}{1-p}\right)=-2.414+2.720 \times 4000000 / 1000000-$ $1.797 \times 3=3.075$ 
Then the probability is

$p=\frac{\exp ^{\operatorname{logit}(p)}}{1+\exp ^{\log i t(p)}}=\frac{\exp ^{3.075}}{1+\exp ^{3.075}}=0.956$

If with higher income and the same number of children, then the probability will increase. In the equation above, if a person has income Rp 4.000.000,- and have 3 children, then obtained the probability value as big as 0.956 . From its value, it can be interpreted the probability of a person willing to pay to reduce the risk will increase to $95.6 \%$.

Logit $(p)=\ln \left(\frac{p}{1-p}\right)=-2.414+2.720$ Income -1.797

Number of children

Logit $(p)=\ln \left(\frac{p}{1-p}\right)=-2.414+2.720 \times 3580000 / 1000000-$ $1.797 \times 4=0.136$

Then the probability is

$p=\frac{\exp ^{\text {logit }(p)}}{1+\exp ^{\operatorname{logit}(p)}}=\frac{\exp ^{0.136}}{1+\exp ^{0.136}}=0.534$

But, if with the same income and a higher number of children, then the probability will decrease. In the equation above, if a person has income $\operatorname{Rp} 3.850 .000$,- and have 4 children, then obtained the probability value as big as 0.534 . From its value, it can be interpreted the probability of a person willing to pay to reduce the risk will decrease to $53.4 \%$.

\section{CONCLUSIONS}

This study gives one equation in the discrete choice model. From age, income, and the number of children variable that obtained from the survey, the significant variables are just income and number of children variables after being analyzed in SPSS program. This shows the difference from the previous study where the age variable included in one of the significant variables.

The p-value of the income variable is 0.025 and the pvalue for the number of children variable is 0.014 , where both variables are significant at the $5 \%$ level (less than 0.05 ). The higher income generates higher probability than the lower income, and the lower number of children generate higher probability than the higher number of children.

From the model obtained, it can be interpreted if with higher income and the same number of children it will increase the probability of a person willing to pay to reduce the risk, but if with the same income and a higher number of children it will decrease the probability of a person willing to pay to reduce the risk.

\section{REFERENCES}

[1] Machsus, I. Prayogo, Chomaedhi, D. W. Hayati, and A. Utanaka, "Road safety analysis on Achmad Yani frontage road Surabaya Road safety analysis on Achmad Yani frontage road Surabaya," in IOP Conf. Series: Materials Science and Engineering, vol. 267, pp. 1-11, 2017.

[2] M. Mohanty and A. Gupta, "Factors affecting road crash modeling," J. Transp. Lit., vol. 9, no. 2, pp. 15-19, 2015.

[3] C. D. Mathers and D. Loncar, "Projections of global mortality and burden of disease from 2002 to 2030," PLoS Med., vol. 3, no. 11, pp. 2011-2030, 2006.

[4] C. J. L. Murray and A. D. Lopez, "Measuring the Global Burden of Disease," N. Engl. J. Med., vol. 369, no. 5, pp. 448-457, 2013.

[5] World Health Organization, "The top 10 causes of death," 2016. [Online]. Available: http://www.who.int/newsroom/fact-sheets/detail/the-top-10-causes-of-death.

[6] H. Widyastuti and C. Mulley, "Evaluation of Casualty Cost of Motorcyclist's Slight Injury In Indonesia," J. East. Asia Soc. Transp. Stud., vol. 6, pp. 3497-3507, 2005.

[7] Z. Sultan, N. I. Ngadiman, F. Dela A.Kadir, N. F. Roslan, and Mehdi Moeinaddini, "Factor Analysis Of Motorcycle Crashes In Malaysia," J. Malaysian Inst. Planners Inst., no. Special Issue IV, pp. 135-146, 2016.

[8] A. S. K. Cheng, K. P. Y. Liu, and N. Tulliani, "Relationship between driving-violation behaviours and risk perception in motorcycle accidents," Hong Kong J. Occup. Ther., vol. 25, pp. 32-38, 2015.

[9] N. Rahmawati and A. Widyanti, "Comparison between motorcyclist' violation behavior and accidents in urban and rural area in Indonesia: A comparative study," IOP Conf. Ser. Mater. Sci. Eng., vol. 277, p. 12026, 2017.

[10] H. Widyastuti, "Valuing Motorcycle Casualties in Developing Countries using Willingness-to-Pay Method: Stated-Preference Discrete Choice Modelling Approach," no. January. Newcastle, England, 2012).

[11] H. Le, T. Van Geldermalsen, W. L. Lim, and P. Murphy, "Deriving Accident Costs using Willingness-to-Pay Approaches - A Case Study for Singapore," in Australasian Transport Research Forum 2011 Proceedings, no. September, p. 16, 2011.

[12] F. S. Koppelman and C. Bhat, "A Self Instructing Course in Mode Choice Modeling : Multinomial and Nested Logit Models by with technical support from Table of Contents," Vol. 28, no. 3, 2006.

[13] M. Ben-Akiva and S. R. Lerman, "Discrete Choice Analysis (Theory and Application to Travel Demand," Massachusetts-London, England: The MIT PressCambridge, 1985.

[14] T. R. L., Overseas Administration Development, 1995.

[15] C. Ghee and A. Astrop, "TRL Report 247: Socioeconomic aspects of road accidents in developing countries," 1997.

[16] B. R. Silcock and Transport Research Laboratory, "Guidelines for Estimating the Cost of Road Crashes in Developing Countries," 2003.

[17] H. Widyastuti, C. Mulley, and D. Dissanayake, "Binary Choices Model To Value Motorcyclist ' S Slight," East. Asia Soc. Transp. Stud. J., vol. 7, no. 1997, pp. 26742685, 2005.

[18] "Peraturan Gubernur Jawa Timur No 75 Tahun 2017 tentang UMK Jawa Timur 2018,” 2017. 